\title{
Demo Abstract: An Improved API and User Experience for the Mortar Testbed
}

\author{
Gabe Fierro \\ UC Berkeley \\ gt.fierro@berkeley.edu
}

\author{
David E. Culler \\ UC Berkeley \\ culler@cs.berkeley.edu
}

\begin{abstract}
The lack of access to real-world building data has long been a significant barrier to the development and evaluation of robust applications and analyses that operate on the built environment. The Mortar platform is an open testbed for portable building analytics containing timeseries data for over 100 buildings as well as rich semantic descriptions of the assets and data sources in buildings. Access to Mortar's data is performed through an API which enforces a staged application architecture intended to simplify the development and deployment of analytics applications across a large number of buildings. In practice, users felt overly constrained by the structure enforced by the API and needed a mechanism for discovering the data available in the testbed. In this demonstration, we present (1) an improved, declarative, API for Mortar that decouples application structure from data access, and (2) an interactive query builder interface that assists users in data discovery and in authoring Brick models.
\end{abstract}

\section{CCS CONCEPTS}

- Information systems $\rightarrow$ Graph-based database models; Information retrieval; $\bullet$ Computing methodologies $\rightarrow$ Model development and analysis;

\section{KEYWORDS}

Smart Buildings; Modeling and Analytics; Data Set.

ACM Reference Format:

Gabe Fierro and David E. Culler. 2019. Demo Abstract: An Improved API and User Experience for the Mortar Testbed. In The 6th ACM International Conference on Systems for Energy-Efficient Buildings, Cities, and Transportation (BuildSys '19), November 13-14, 2019, New York, NY, USA. ACM, New York, NY, USA, 1 page. https://doi.org/10.1145/3360322.3361008

Permission to make digital or hard copies of part or all of this work for personal or classroom use is granted without fee provided that copies are not made or distributed for profit or commercial advantage and that copies bear this notice and the full citation on the first page. Copyrights for third-party components of this work must be honored For all other uses, contact the owner/author(s).

BuildSys '19, November 13-14, 2019, New York, NY, USA

(C) 2019 Copyright held by the owner/author(s).

ACM ISBN 978-1-4503-7005-9/19/11.

https://doi.org/10.1145/3360322.3361008 